\title{
Prelabour Rupture of Membrane : Maternal and Foetal Outcomes
}

Monira Jamal ${ }^{1 *}$

Rajat Kumar Biswas²

'Department of Obstetrics and Gynaecology Chattgram Maa-O-Shishu Hospital Medical College Chattagram, Bangladesh.

${ }^{2}$ Department of Obstetrics and Gynaecology Chittagong Medical College

Chattagram, Bangladesh.

\footnotetext{
*Correspondence to:

Dr. Monira Jamal

Resident Surgeon

Department of Obstetrics and Gynaecology

Chattgram Maa-O-Shishu Hospital Medical College

Chattagram, Bangladesh.

Mobile : +88017182768 80

Email:monira.jamal@yahoo.com
}

Date of Submission : 15.06 .2020

Date of Acceptance : 26.08 .2020

www.banglajol.info/index.php/CMOSHMCJ

\begin{abstract}
Background: The leading cause of perinatal morbidity and mortality is prematurity in developed and underdeveloped countries. In one third of the patients with preterm labour, there is associated premature rupture of membranes. The study was conducted to evaluate the clinical presentation of Pre-labour Rupture of Membrane (PROM) in pregnancy and obstetric outcome.
\end{abstract}

Materials and methods: This is a cross sectional study carried out in the Department of Obstetrics and Gynaecology, Bangabandhu Sheikh Mujib Medical University, Dhaka, between September 2013 to February 2014. About 50 women having PROM with more than 32 weeks gestational age who admitted in the above department for delivery were enrolled in this study.

Results: The mean age was found $27.4 \pm 4.42$ years with range from 17 to 41 years. Forty eight percent of PROM patient were primi and 52.0 percent of patients were multigravida. Six percent patients were illiterate. Almost two third patients were housewives. More than half (54.0\%) of the patients were came from poor class income group family. Majority (64.0\%) patients had term PROM (>37 weeks) gestational age and the mean gestational age was $38.1 \pm 2.7$ weeks with range from 3240 weeks. More than half (54.0\%) didn't received any antenatal checkup. A total of (56.0\%) patients had associated disease, out of which anaemia was more common. Twelve percent had diabetes mellitus and $8.0 \%$ had UTI infection. Almost two third (64.0\%) was vaginal delivery and $18(36.0 \%)$ were caesarean section and common indication for caesarean section was fetal distress (38.9\%). Two third patients were healthy and 17 patients had morbidities, wound infection is highest (29.4\%). The mean birth weight was found $2.74 \pm 0.7 \mathrm{~kg}$. APGAR score $>7$ at 1 minute was found (92.0\%) and (94.0\%) at 5 minutes of birth of baby after birth. Fetal outcome take home alive (98.0\%) and neonatal death $2.0 \%$. Among 50 foetus morbidity develop in 26 cases. Among them respiratory insufficiency is highest (38.5\%).

Conclusion: Motivation of the patients, health education, improvement of nutritional status of mother, neonatal care service, early diagnosis, treatment, overall institutional delivery is needed for reduction of neonatal morbidity and mortality, as well as maternal morbidity.

Key words : Pre-labour Rupture of Membrane (PROM); Maternal and perinatal morbidity and mortality; Pregnancy.

\section{INTRODUCTION}

Pre-labor Rupture of Membrane (PROM) is the spontaneous rupture of membrane before the onset of active labor. The incidence of PROM ranges from about 5\% to $10 \%$ of all deliveries, and PROM occurs in approximately $3 \%$ of all pregnancies. Approximately $70 \%$ of cases of PROM occur in pregnancies at term ${ }^{1}$. 
Rupture of membranes is found to be related with bacterial infection. Studies have shown that the changes in the elasticity of the membranes were secondary to a decrease in specific collagen make up ${ }^{2}$.

PROM is also related with cervical incompetence, documented cervico-vaginal infection hypertensive diseases, recent coitus, malpresentation, antepartum hemorrhage and inappropriate nutrition $^{2,3}$. PROM is found more common in low socio-economic class patient with inadequate prenatal care and inadequate weight gain during pregnancy. Rupture of membrane often leads to the onset of labor. In term pregnancy, rupture of membrane leads to spontaneous labor in $70 \%$ case within 24 hours ${ }^{3}$. The history of leaking fluid or gushing of water from vagina is diagnostic over $90 \%$ of the time. Different tests like nitrazine, fern, evaporation and diamine oxidase test are done to confirm PROM.

Chorioamnionitis occurs frequently in patients with PROM and monitoring of the patient is directed at the early recognization of infection. The overall incidence of chorioamnionitis ranges from $4.2 \%$ to $10.5 \%{ }^{4,5}$. Maternal infection after PROM may be severe and has an overall mortality rate of 1 in $5400^{6}$.

The management of pre-labour rupture of membranes at term is still a matter of debate and varies from centre to centre. While active induction of Labor after pre-labour rupture of membranes has resulted in a lower risk of maternal and fetal sepsis in some studies, it has also been associated with a higher caesarean section rate in others ${ }^{7}$.

The result of largest randomized controlled trial on pre-labour rupture of membranes to date found that active labour induction with oxytocin or vaginal prostaglandin E2 (PGE2) versus expectant management resulted in similar rates of caesarean sections and neonatal infections, although the risk of maternal infection was lower with oxytocin induction ${ }^{8}$.

So, the aim of this study is to evaluate the clinical presentation of Premature Rupture of Membrane (PROM) in pregnancy and obstetric out come and also to find out the effect of PROM on maternal health so that we can pay more attention for the correct diagnosis and management of PROM that can reduce maternal and perinatal mortality and morbidity.

\section{MATERIALS AND METHODS}

It was a cross sectional study carried out in the Department of Obstetrics and Gynecology, Bangabandhu Sheikh Mujib Medical University (BSMMU) Dhaka. The study population were 50 women with PROM. The study based on mutually inclusive criteria which included women having PROM with any gravida, Gestational age more than 32 weeks and duration of spontaneous rupture of membrane before initiation of labour. Patient with rupture of membrane with established labour, rupture of membrane with APH, severe pre-eclampsia, eclampsia, malpresentation and congenital malformation of baby were excluded from the study. The data were collected by interview, physical \& lab examination using a structured questionnaire containing all the variables of interest. For evaluation of perinatal and maternal outcome all sample cases were followed up to 7 days after delivery. Statistical analyses were carried out by using the Statistical Package for Social Sciences version 16.0 for Windows (SPSS Inc., Chicago, Illinois, USA).

\section{RESULTS}

Table I : Age distribution of the study patients $(n=50)$.

\begin{tabular}{lcc} 
Age (Years) & No. of patients & Percentage \\
$15-19$ & 5 & 10.0 \\
$20-24$ & 17 & 34.0 \\
$25-29$ & 20 & 40.0 \\
$30-34$ & 6 & 12.0 \\
$35-39$ & 1 & 2.0 \\
$>39$ & 1 & 2.0 \\
Mean \pm SD & $27.4 \pm 4.42$ & \\
Range (Min, max) & $(17,41)$ & \\
\hline
\end{tabular}

Majority PROM were in 25-29 years age group.

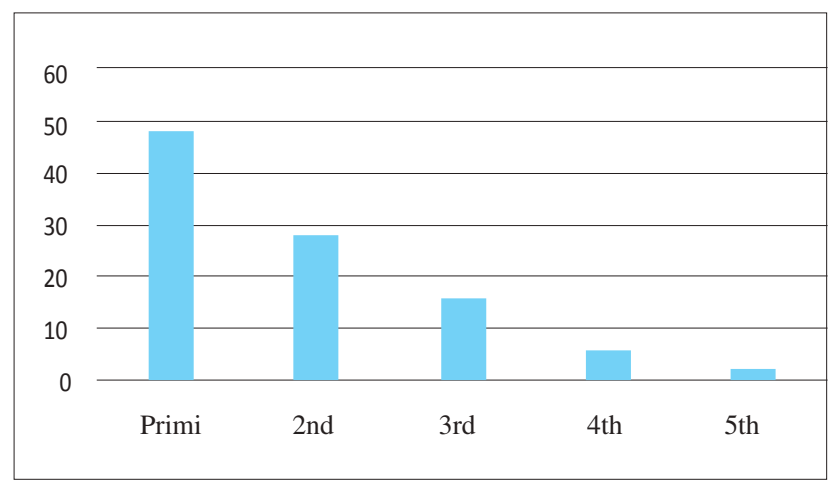

Figure 1 : Distribution of the study patients according to incidence of parity $(n=50)$.

Most (52.0\%) of the patients were multigravida.

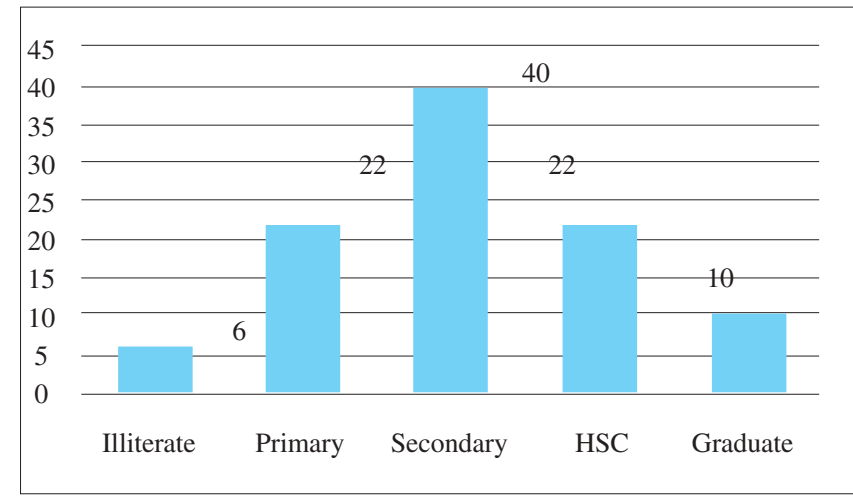

Figure 2 : Distribution of the study patients according to educational status $(\mathrm{n}=50)$.

Among low income family and patients with secondary level of education incidence of PROM is common. 
Table III : Distribution of the study patients according to clinical presentation $(\mathrm{n}=50)$.

\begin{tabular}{lcc} 
Clinical presentation & Number of patients & Percentage \\
Gestational age (Weeks) & 6 & \\
$32-34$ & 12 & 12.0 \\
$35-36$ & 32 & 24.0 \\
$\geq 37$ & & 64.0 \\
& $38.1 \pm 2.7$ & \\
Mean \pm SD & 32,40 & \\
Range (Min, Max) & & \\
Antenatal Checkup (ANC) & 15 & 30.0 \\
Regular & 8 & 16.0 \\
Irregular & 27 & 54.0 \\
No Antenatal checkup & & \\
Time interval between PROM and Delivery & & \\
$\leq 15$ hours & 27 & 54.0 \\
$16-30$ hours & 12 & 24.0 \\
$\geq 30$ hours & 11 & 22.0 \\
\hline
\end{tabular}

Majority of the patients $(64.0 \%)$ had term PROM ( $\geq 37$ weeks) and only $15(30.0 \%)$ patients were under regular antenatal checkup.

Table IV : Distribution of the study patients according to risk factors $(n=50)$.

$\begin{array}{lcc}\text { Risk Factors } & \text { Number of patients } & \text { Percentage } \\ \text { Anaemia } & 13 & 26.0 \\ \text { Infections } & 7 & 14.0 \\ \text { Diabetes Mellitus } & 6 & 12.0 \\ \text { Multiple Pregnancy } & 2 & 4.0 \\ \text { Poly hydramnios } & 1 & 2.0 \\ \text { Cervical incompetence } & 1 & 2.0\end{array}$

Anaemia, infections and diabetes mellitus are important risk factors for PROM.

Table $\mathbf{V}$ : Mode of delivery $(\mathrm{n}=50)$.

\begin{tabular}{lcc} 
Mode of delivery & No. of delivery & Percentage \\
Vaginal & 32 & 64.0 \\
Cesarean section & 18 & 36.0 \\
\hline
\end{tabular}

Most of the patients with PROM delivered vaginally.

Among 50 patients, 33 patients were healthy and 17 patients had morbidities.

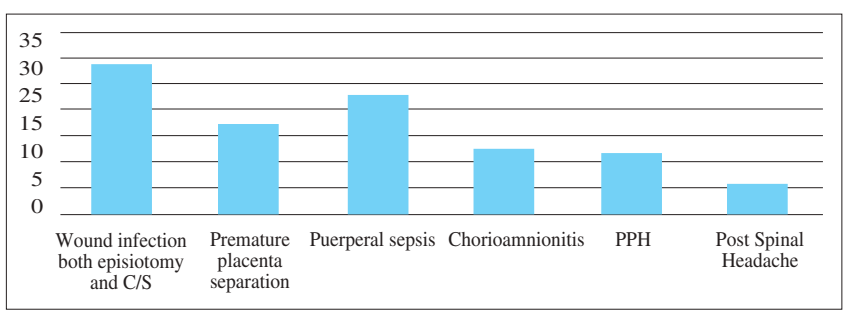

Figure 3 : Maternal morbidity ( $\mathrm{n}=17)$.

Wound infection (Both episiotomy \& C/S) was the highest maternal morbidity in PROM.
Table VI : Birth weight of babies $(\mathrm{n}=50)$.

\begin{tabular}{|c|c|c|}
\hline Birth weight (kg) & Number of babies & Percentage \\
\hline$<1.5$ & 2 & 4.0 \\
\hline $1.6-2.5$ & 20 & 40.0 \\
\hline $2.6-3.0$ & 18 & 36.0 \\
\hline $3.1-3.5$ & 8 & 16.0 \\
\hline$>3.5$ & 2 & 4.0 \\
\hline Mean \pm SD & \multirow{2}{*}{\multicolumn{2}{|c|}{$\begin{array}{r}2.74 \pm 0.7 \\
(1.8-3.5)\end{array}$}} \\
\hline Range (Min-Max) & & \\
\hline
\end{tabular}

Majority (40.0\%) babies were birth weight 1.6-2.5 kg. Most of the deliveries were done after 37 weeks.

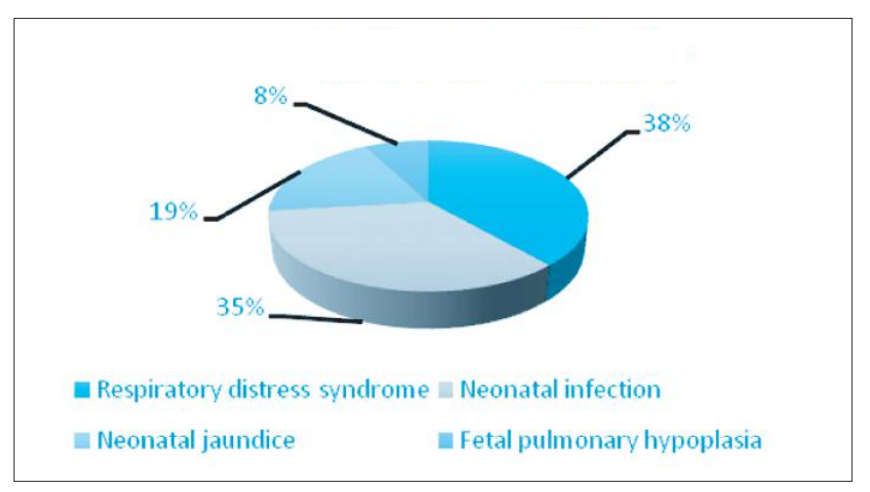

Figure 4 : Perinatal morbidity $(\mathrm{n}=26)$.

Among 26 perinatal morbidity respiratory distress syndrome is highest.

Table VII : Perinatal outcome $(\mathrm{n}=50)$.

$\begin{array}{lcc}\text { Perinatal outcome } & \text { Number of babies } & \text { Percentage } \\ \text { Take home alive } & 49 & 98.0 \\ \text { Neonatal death } & 1 & 2.0 \\ \text { Still birth } & 0 & 0.0\end{array}$

Take home alive babies $98.0 \%$ and neonatal death $2.0 \%$.

\section{DISCUSSION}

In this study majority $20(40 \%)$ patients were age belonged to 25-29 years which is similar to other studies done by Begum, Tasnim, Moretti and Sibai ${ }^{9-11}$.

In this current study it was observed that 48.0 percent of PROM patient were primi and 52.0 percent of patients were multigravida. Begum \& Chowdhury observed the incidence in multi about 54.0 percent and Moretti and Sibai observed 71 percent incidence in multigravida ${ }^{12,11}$.

Most (40.0\%) of the patients had secondary level of education, $6.0 \%$ illiterate and $10.0 \%$ were graduate level. More than half $(54.0 \%)$ of the patients were came from low income family, 18 $(36.0 \%)$ came from lower middle- income group family, Akter et al mentioned in their study that most of the patients came from low socio-economic status and have low level of education $^{13}$. In another study, Omar et al obtained $56.0 \%$ study patients belonged to low economic class and $33.0 \%$ from middle class $^{14}$. 
Majority (64.0\%) patients had term PROM (>37 weeks) gestational age and the mean gestational age was $38.1 \pm 2.7$ weeks with range from 32-40 weeks. Akter et al showed the mean gestational age was 35 weeks. Here lack of quality care may be the cause of PROM $^{13}$.

Regarding antenatal checkup15(30.0\%) patients received regular antenatal checkup, $8(16.0 \%)$ received irregular antenatal check and 27(54.0\%) not received antenatal checkup. Akter et al showed irregular antenatal care in their study patients, which is consistent with the current study ${ }^{13}$.

It was observed that majority $26.0 \%$ had anaemia, $12.0 \%$ had diabetes mellitus, $7(14.0 \%$ ) had infection (UTI and lower genital tract infection) and only $1(2.0 \%)$ had polyhydramnios. Akter et al mentioned that $72.0 \%$ women had UTI and lower genital tract infection ${ }^{13}$. PROM is malnutrition and poverty related disease, which is comparable with the current study. Antenatal care is an important tool to prevent PROM by identifying the risk factors and its management.

In this series it was observed that mode of delivery in 50 patients among them $64.0 \%$ was vaginal delivery and $18(36.0 \%)$ were caesarean section. Nili and Shams Ansar and Akter et al showed $65.6 \%$ and $56.0 \%$ women were underwent cesarean section respectively ${ }^{15,13}$. In another study, Omar et al and Triniti et al reported that $88.0 \%$ and $73.0 \%$ had vaginal delivery respectively ${ }^{14,16}$. In this study, as most of the patients came at term, so maximum number of patient's delivered vaginally.

Caesarean section was not indicated for PROM rather for it's complications like fetal distress (38.9\%), 4(22. 2\%) had prolonged labour, 3(16.7\%) had unfavorable cervix and 2(11.1\%) had bad obstetric history, Chorioamnionitis. Omar et al documented that fetal distress was the commonest indication seen in $4.4 \%$ cases followed by failed induction in $3.3 \%$ cases and previous caesarean section in $1.1 \%$ cases $^{14}$.

In this current study it was observed that among 50 patients 33 patient were healthy and 17 patients had morbidities. Most common morbidities were wound infection (Both episiotomy \& CIS) 3(17.6\%) had premature placental separation, 4(23.5\%) had puerperal sepsis and $2(11.8 \%)$ had chorioamnionitis. Begum $\mathrm{A}$ and Chowdhury $\mathrm{S}$, observed common maternal morbidity were chorioamnionitis $(11 \%)$ and puerperal sepsis $(7 \%)^{12}$. Majority $(40.0 \%)$ babies birth weight range is $1.6-2.5 \mathrm{~kg}$. The mean birth weight was found $2.74 \pm 0.7 \mathrm{~kg}$ with range from 1.8 to $3.5 \mathrm{~kg}$, which is similar with Nili and Shams Ansari study, where the authors found the mean birth weight was $2.21 \pm 0.76 \mathrm{~kg}^{15}$.
Regarding perinatal outcome take home alive (98.0\%) and neonatal death $2.0 \%$.

The primary determinant of neonatal morbidity and mortality is gestational age at delivery. In general, prognosis is good after 32 weeks' gestation as long as no other complicating factor. Low APGAR scores and neonatal hyper bilirubinemia were more frequent when preterm delivery was due to premature rupture of the membranes than when it was due to other causes. This was mainly the result of the high frequency of amnioticfluid infections associated with the premature membrane ruptures. In this study it was observed that among 50 cases, 26 suffered from perinatal morbidity. Among them respiratory distress syndrome is highest (38.5\%) neonatal infection (34.6\%) neonatal jaundice $(19.2 \%)$ and fetal pulmonary hypoplasia (7.7\%). The largest study to date, as well as meta-analysis of studies has also demonstrated that antibiotic treatment reduces the risks of maternal chorioamnionitis, neonatal respiratory distress syndrome and neonatal sepsis ${ }^{17}$.

\section{CONCLUSION}

This study was undertaken to determine the factors associated with premature rupture of membrane in pregnancy and to evaluate the maternal/perinatal morbidity and mortality of PROM which is associated with increased foetal morbidity and mortality. Demographic variables can be applied to develop risk scoring so as to identify high-risk cases and treating them in time to prevent ascending infection along with its complications.

\section{RECOMMENDATIONS}

Quality antenatal screening will help to identify the risk factors for PROM and morbidity could be prevented and further studies may be designed in a large scale to compare and contrast the accuracy and efficacy of different management approach.

\section{DISCLOSURE}

Both the authors declared no competing interest. 


\section{REFERENCES}

1. Gibbs R, Karlan B, Haney A, Nygaard I. Danforth's obstetrics and gynecology. 10th ed. Philadelphia: Lippincott Williams \& Wilkins. 2008.

2. Michel T, Parsons, Williams N, Spellacy. Premature rupture of membranes. Danforth's Obstetrics and Gynecology. Editor James R. Scott et. AI. Lippincott Williams and Wilkins, 8th edition. 1999; 269-276.

3. Kodkany BS, Telang MA. Premature rupture of membranes. A study of 100 cases. J. Obstet Gynaecol. 1991; 41(4): 492-496.

4. Newton ER, Prihoda TJ, Giggs RS et al. Logistic regression analysis of risk factors for intra- amniotic infection. Obstet Gynaecol. 1989; 75: 571- 575 .

5. Soper DE, Mayhall CG, Dalton HP. Risk factor for inraamniotic infection. A prospective epidemiological study. Am J obstet Gynaecol. 1989; 161: $562-568$

6. Labherz TB, Hellmann LP, Madding R. et al. Doubl blind study of premature rupture of membranes. Am J Obstet Gynaecol. 1963; 87: 218.

7. Shetty A, Stewart K, Stewart G, Rice P, Danielian P, Templeton A. Active management of term prelabor rupture of membranes with oral misoprostol. BJOG. 2002; 109: 1354-1358.

8. Tan BP, Hannah ME. Prostaglandins versus oxytocin for prelabour rupture of membranes at term. Cochrane Data base Syst Rev. 2000; (2): CD000159.

9. Begum D. Maternal and fetal complication of premature rupture of the membranes: A case control study [dissertation]. Dhaka Medical College of physician and surgeon. 1997.

10. Tasnim S. Clinical profile and outcome of premature rupture of membranes in Dhaka Medical College Hospital: A study of 55 cases [Dissertation] Dhaka Medical College of physician and surgeon. 1995.

11. Moretti M, Sibai BM. Maternal and perinatal outcome of expectant management of premature rupture of membranes in the mid-trimester. AM J obstetrics gynecology. 1998; 2: 121-129.

12. Begum A and Chowdhury S. Premature Rupture of Membranes (PROM): A clinical evaluation pf 60 cases. J lnst Postgrad Med Res. 1991.

13. Akter S, Akther R, Rashid M. Preterm Prelabour Rupture of the Membrane \& Fete-Maternal outcome: An Observational Study. J Bangladesh Coli Phys Surg. 2010; 28: 17-23.

14. Omar AAA, Ayyad E and Nabateh H. Preterm Premature Rupture of Membranes (PPROM): Incidence and Outcome. Journal of the Bahrain Medical Society. 2005; 17(1): 20-25.

15. Nili F and Ansari AAS. Neonatal Complications of Premature Rupture of Membranes. Acta Medica lranica. 2003; 41(3): 175-179.

16. Triniti A, Suthatvorawut S, 0-Prasertsawat P. Epidemiologic Study of Cervical Swab Culture in Preterm Premature Rupture of Membrane (PPROM) at Ramathibodi Hospital. Thai Journal of Obstetrics and Gynaecology. 2008; 16:173-178.

17. Mercer BM. Preterm Premature Rupture of Membrane Obstet Gynaecol. 2003; 101: 178-193. 